\title{
Abundance, Distribution and Population Structure of Mountain Nyala (Tragelaphus buxtoni) in Hanto Controlled Hunting Area, Southeastern Ethiopia
}

\author{
Dejene Worku $^{1^{*}}$ and Demeke Datiko ${ }^{2}$ \\ ${ }^{1}$ Department of Environmental Science, Madda Walabu University, Ethiopia \\ ${ }^{2}$ Ethiopian Biodiversity Institute, Hawassa Center, Hawasa, Ethiopia
}

"Correspondence author: Dejene Worku, Department of Environmental Science, Madda Walabu University, P.O. Box 247, Bale-Robe, Ethiopia, Tel: 251111239706 Email: dworkud@gmail.com

Received date: May 31, 2017; Accepted date: July 13, 2017; Published date: July 20, 2017

Copyright: @ 2017 Worku D, et al. This is an open-access article distributed under the terms of the Creative Commons Attribution License, which permits unrestricted use, distribution, and reproduction in any medium, provided the original author and source are credited.

\begin{abstract}
An investigation on abundance, distribution and population structure of endemic and endangered mountain nyala (Tragelaphus buxtoni) was carried out in Hanto controlled hunting area between 2015 and 2016 for both wet and dry seasons. The objective of investigation was to compile baseline data on abundance, distribution and population structure of mountain nyala in the controlled hunting area. To achieve the objective, five major habitat types (Erica vegetation, Woodland, Bamboo forest, Reverine forest and Grassland habitat) were identified and $21 \%$ of each habitat was surveyed. Sample counts of mountain nyala was carried out using random line transect sampling method in an area of $39.9 \mathrm{~km}^{2}$ from the total area of $190 \mathrm{~km}^{2}$ to estimate the population size and to identify their distribution. The estimated populations of mountain nyala were $531.9 \pm 49.3$ individuals. Male mountain nyala comprised $37.5 \%$, females were $50.9 \%$ and young's of both sexes were $11.6 \%$ of the total population. The male to female sex ratio was 1:1.36. Age structure was dominated by adults, which constituted $61.2 \%$ of the total population. The animals were distributed in all the five habitat types. Hence, the study revealed that, the controlled hunting area harbors significant populations of endemic mountain nyala. As a result, it can serves not only as hunting concession but also as an important core protected area for the country's wildlife conservation and tourist attraction area in the future.
\end{abstract}

Keywords: Abundance; Distribution; Hanto controlled hunting area; Mountain nyala

\section{Introduction}

Globally, a total of about 5,416 species of animals exist, out of which 1,150 species of animals are recorded in Africa [1]. Ethiopia is one of African countries which are a home for highly diversified faunal species composition [2]. The country has a land area of 1.12 million square kilometers and a wide variety of topography and climate. There is a great variation in altitude, ranging from 116 meters below sea level in the Danakil depression of Afar region [3] to 4,620 $\mathrm{m}$ asl at the top of Mount Ras Dashen of Semin Mountain [4].

Ethiopia currently possesses more than 284 species of animals of which 31 are endemic [5]. Out of this, 12 of them are endemic large animals, including mountain nyala [6]. The high level endemicity of animals in Ethiopia is attributed to the large extent of highlands, isolated from the rest part of Africa and the variability of climatic factors among different habitats [7].

Despite, Ethiopia is among few African countries with high mammal species diversity, its mammalian resource is significantly degrading. Hence, for effective designing, implementing and the success of conservation program, it is imperative to monitor the status, distribution and trends in the population of target species [8].

Protected areas are one of biodiversity conservation centres and major tourism assets for a nation, particularly for developing countries like Ethiopia through providing sustainable benefit to the local community while supporting for the maintenance and rehabilitation of the protected areas themselves [9]. Despite, different efforts were made in the country for wildlife conservation, human activities like habitat loss, habitat degradation, habitat fragmentation, hunting and land clearance for farming and settlement, land degradation due to overgrazing and illegal encroachments to the conservation areas are the most series problem of the $21^{\text {st }}$ century [10].

This condition particularly affects the distribution patterns of large animals as they wander in search of preferred habitats which are found in patchy habitats of protected area [11]. As a result, some of the rare and endangered mammalian species have shifted their original range and occur in a few habitats in some places. Moreover, BIDNTF [12] indicated that even the existing protected area networks are not being intensively monitored to see trends and most of them lack basic data and management plans in Ethiopia

The Bale Mountain highlands of southeastern Ethiopia are unique in Africa and are known as centre of endemism. They encompass Africa's largest alpine plateau and contain the largest populations of Africa's most charismatic species like mountain nyala [13], which is the species of present study. They also harbor an exceptionally high number of other species endemic to Ethiopia.

Mountain nyala (Tragelaphus buxtoni) is African Artiodactyls of the family Bovidae antelope species found only in Ethiopia [14]. Their abundances are drastically declining mainly due to the impact of rapid human population growth [15]. It is the most important trophy species in Ethiopia as well as in the current study site. Even though, the mountain nyala is currently categorized as an endangered species by 
IUCN [16]. It is generating more than 1.4 million US dollars per year for the country through trophy hunting [17].

Hence, the current study site, Hanto controlled hunting area (Hanto $\mathrm{CHA}$ ) is part of Bale Mountain highlands and one of the recently established CHA in Bale. Currently the area is leased to a local investor with the name of Rocky Valley Hunting Safari Privet Limited Company. The CHA is found in between Dinsho, Agarfa and Adaba districts in the North-West direction of Bale Mountains National Park (BMNP). As per knowledge of investigators, there was no scientific base line data concerning abundance, distribution and age/sex structures. Thus, the present study is aimed at contributing to fill existing gap though investigating the current ecological information of the animal.

\section{Materials and Methods}

\section{The study area}

The current study site is Hanto controlled hunting area (Hanto CHA). It is located in the Southeastern part of Ethiopia, in the Oromia administrative region of Bale Zone, Dinsho district. Hanto CHA is about $378 \mathrm{~km}$ from Addis Ababa to Southeastern direction. The area is established in 1998, and leased to a local professional hunting company. Therefore, currently the local NGO known as Rocky valley hunting safari P.L.C, hold the rights for hunting throughout the area [18].

The study site is located within geographic coordinates of $7^{\circ} 04^{\prime}-7^{\circ}$ $20^{\prime} \mathrm{N}$ latitude and $39^{\circ} 34^{\prime}-39^{\circ} 50^{\prime} \mathrm{E}$ longitude along the Southeastern highlands of Ethiopia (Figure 1). The controlled hunting area encompasses an area of $190 \mathrm{~km}^{2}$. It is characterized by a chain of mountains and sub-alpine forest ecosystem. Hanto is located at about 7 $\mathrm{km}$ North-West direction from the border of Bale Mountain National Park.

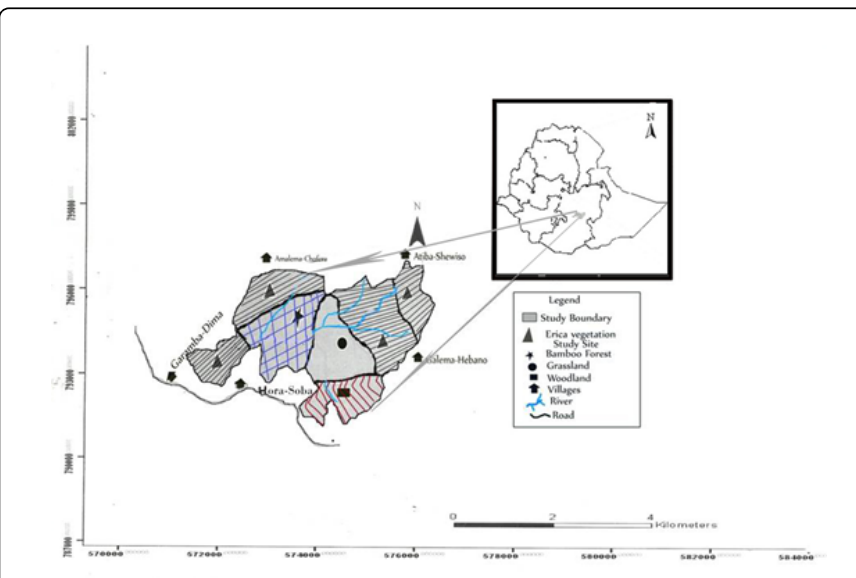

Figure 1: Map of study area with location of study sites.

The topography of the study area is characterized by high and rugged mountainous ridges with high slopes and gently rolling steep hills with all of the areas elevation ranging from 2,980-3,585 $\mathrm{m}$ asl. As the area is very close to BMNP, it is also characterized by SubAfrolapine and upper montane ecosystem vegetation type which are dominated by Hagenia abyssincia, Hypericum revolutum, Juniperus procera, Sinarundinaria alpina and Erica vegetation.
The mean annual temperature of the area is $10.9^{\circ} \mathrm{C}$ while the mean lowest and highest temperatures are 4.7 and $17.1^{\circ} \mathrm{C}$ respectively. March is the hottest month $\left(18.75^{\circ} \mathrm{C}\right)$ and December is the coldest $\left(2.01^{\circ} \mathrm{C}\right)$ months. The area has a bimodal local climate with two wet seasons that have heavy and small rains. The data obtained from National Meteorological Agency of Bale branch directorate shows the area were having the mean annual rainfall of up to $1120 \mathrm{~mm}$ for the past ten years (2004-2014). The heavy rains occur from July to October, with the highest peak in August and the small rains from March to June, with a peak in April (NMABD, 2015).

\section{Methods}

During survey, materials used for data collection were includes: GPS, digital camera, $7 \times 35$ binocular, range finder, compass and animals field guide, tape meter, data sheet, field tents, rain coat and sleeping bag. In order to collect basic information about the location, climatic condition, topography, habitat types and approximate size of the study area a preliminary survey was carried out in the first two weeks of February, 2015 in the CHA. Vegetation types, landscape of the study area and wildlife distribution and representative habitat sites and their size were identified.

Based on the preliminary observation, the classification of vegetation type was carried out in the proposed study area. The survey revealed that the vegetation cover and topography of the area was not homogenous. For the purpose of this investigation, the entire study area was clustered in to five major habitat types; namely Ericaceous vegetation, Hygenea abysinica dominated woodland, riverin forest, bamboo forest and grassland habitat. Four sample areas for Erica vegetation and one sample area for each of the bamboo forest, Hagenia abyssinica dominated woodland, grassland and reverin forest habitats were identified. Mountain nyala abundance, structure and patterns of distribution in the area were examined using a representative random sampling design of line transects method [19]. Line transects survey was selected because it is the method most commonly used distancebased method for surveying large animals like African ungulates and livestock in preference to point transects [20].

A total of 23 transects were marked on the identified eight sample area. The number of transects that laid on the major habitats types were based on the total size of the habitat. The representative transects that cross each habitat were randomly selected in order to represent all of the major habitat type. During this study, $21 \%$ of the total study area was surveyed as indicated below following the methods used by Dereje et al. and Girma et al. [6,21].

Erica vegetation zone was the first largest habitat that covers about $129.2 \mathrm{~km}^{2}$ of the study area. In this habitat a total of 12 transect with $7.5 \mathrm{~km}$ length and $300 \mathrm{~m}$ strip width each $(150 \mathrm{~m}$ on each side of the transect line) were marked. Hagenia abyssinica dominated Wood land zone was the second largest habitat that covers about $30.4 \mathrm{~km}^{2}$ of the study area. In this habitat 2 transects with $8 \mathrm{~km}$ length and $400 \mathrm{~m}$ strip width each was marked. It was cover a total area of $6.4 \mathrm{~km}^{2}$ of the sample area. Reverine forest was the third largest habitat that covers about $15.2 \mathrm{~km}^{2}$ of the study area. In this habitat 3 transects with $5.5 \mathrm{~km}$ length and $200 \mathrm{~m}$ strip width each was marked. Bamboo forest zone was the fourth largest habitat that covers about $9.5 \mathrm{~km}^{2}$ of the study area. In this habitat 4 transects with $5 \mathrm{~km}$ length and $100 \mathrm{~m}$ strip width (50 $\mathrm{m}$ on each side) each was marked. Grassland was the smallest habitat that covers about $5.7 \mathrm{~km}^{2}$ of the study area. In this habitat 2 
transects with $1.5 \mathrm{~km}$ length and $400 \mathrm{~m}$ width (200 m on each side) was marked.

Each of this transect-line was located randomly in the study area in each of the habitat type using GPS. A space of about 200-500 $\mathrm{m}$ was left between consecutive transects based on vegetation type to avoid double counting. All transects were laid roughly parallel to each other and the same transects were used for both wet and dry seasons survey. Each transects in a given habitat were surveyed at the same time twice per day. The transect lines were demarcated using natural boundaries like rivers, streams, rocks big trees etc.

The data were collected once for the dry season and twice for the wet season. Data collection was carried out on April, 2015 and August, 2015 months to accommodate the wet seasons, and January, 2016 to accommodate the dry season. Data collections were focused on the population size, population density, group size and type age and sex categories, habitat preference and distribution of the animals. As done by Buckland et al. [19] a line-transect census method were employed to assess the current abundance and distribution of the animals.

Of the animal is possible. During the assessments, 20 days and night were spent per counting seasons for the survey. Sex, age category of the animals, group size and composition were recorded during the observations. Data collection was made through direct observations with naked eye and/or by using $7 \times 35$ binoculars. As indicated by Yalden et al. [5] the direct observational technique is most Eight trained people were involved in the research to assist data collection process. Based on the number of transects, four patrolling teams with two person at each transect were assigned. Prior to data collection training was given for the patrolling team on how to operate the GPS receiver and data recording on data sheet. The transect lines in each sample zone was fixed to assist the foot counts by making use of standard transect counting methods [22].

The field survey times were morning and afternoon (between 6:00-11:00 am. and 3:00-6:00 pm), when the animals are more active for feeding and maximum observation appropriate for medium to large sized animals. Further, silent detection method like traveling against direction of wind was also used to minimize disturbances [5]. Indirect evidences such as fresh fecal droppings, feeding marks were used to confirm doubtful observations of the animals. Furthermore, stopping after every $50 \mathrm{~m}$ for about a minute were followed to listen for animals or branch movements and vocalizations, to maximize the counting of individuals.

To increase the accuracy of estimation of the populations, each transect was repeated six times both during the wet and dry seasons [23]. Information on the approximate demographic composition and structure, like: age class and sex ratio, was used to predict the general trend of the animals population. Each individual sex and age classes were identified and categorized following Dereje et al.; Befekadu et al. $[6,24]$. Binoculars were used for proper sex and age identification. Age and sex determination were carried out based on body size, presence or absence of horn, horn size and coat colour.

The individual or individuals in a herd were recorded as Adult Male (AM), Adult Female (AF), Sub-adult Male (SAM), Sub-adult Female (SAF) and young of both sex [1]. Sex ratios for the animals were obtained from direct count of the animals using the methods of Hillman [25]. As suggested by Dereje et al. Yosef et al. [6,26], solitary individuals were considered as a group of one for statistical analysis. Following the method of individuals was considered to be in the same group if the distance between them was less than $50 \mathrm{~m}$ [24]. The distribution of mountain nyala was assessed during ground survey. In each survey area, whenever the animals sighted: GPS location, group size and habitat types were recorded [27]. Group size and group composition, age, total number in the herd and other special features of the animal encountered were used to avoid double counting.

\section{Data Analysis}

For data analysis SPSS computer software version 20 and descriptive statistics (mean, frequency, Standard error and percentage) were used. Population estimates of the animals for wet and dry seasons were compared using Chi-square test at $95 \%$ confidence interval. Chi-square tests were used also to compare sex, age category and distribution at 0.05 levels of significance. For density and population estimation of the animals, the following methods were also used. Estimation for Density: $\mathrm{D}=\mathrm{N} / 2 \mathrm{LW}$, where $\mathrm{D}=$ Estimated density of animals in each habitat, $\mathrm{N}=$ number of animals seen, $\mathrm{L}=$ Length of transect lines and $\mathrm{W}=$ Mean perpendicular distance of animals seen. The population sizes of animals in each habitat were estimated by multiplying the population Density (D) with total extent of each habitat type by the present study area (A) following the method of Sutherland [20]. Finally, the sum of estimates in each habitat type will give the total estimates of the animal in the CHA.

\section{Results}

Based on field survey, the results of sample counts of mountain nyala for wet and dry seasons in the CHA is given in Table 1. On average, 96 individuals of mountain nyala were recorded during wet season. But, 128 individuals of mountain nyala were recorded during dry season. The mean numbers of individuals observed during both seasons of the study were 112 . The mean population estimate for the $\mathrm{CHA}$ was $531.9 \pm 49.3$. There was significant difference on the number of mountain nyala observed during wet and dry seasons $\left(\chi^{2}=4.57\right.$, $\mathrm{df}=1, \mathrm{p}<0.05)$.

\begin{tabular}{|c|c|c|c|c|c|c|c|}
\hline \multirow[t]{2}{*}{ Types of Animal } & \multirow[t]{2}{*}{ Seasons } & \multicolumn{6}{|c|}{ Habitat Types } \\
\hline & & Erica & Wood L & Reverine F & Bamboo & Grass L & Total \\
\hline \multirow[t]{5}{*}{ Mountain nyala } & Wet & 53 & 14 & 15 & 0 & 14 & $96 \pm 8.9$ \\
\hline & Dry & 72 & 17 & 24 & 6 & 9 & $128 \pm 12.0$ \\
\hline & Mean & 62.5 & 15.5 & 19.5 & 3 & 11.5 & $112.0 \pm 10.4$ \\
\hline & Density & 2.3 & 2.4 & 6.1 & 1.5 & 9.6 & $4.4 \pm 1.5$ \\
\hline & P. Estimates & 297.2 & 73 & 92.7 & 14.3 & 54.7 & $531.9 \pm 49.3$ \\
\hline
\end{tabular}

Table 1: Population estimates of mountain nyala (Mean \pm SE). 
Citation: Worku D, Datiko D (2017) Abundance, Distribution and Population Structure of Mountain Nyala (Tragelaphus buxtoni) in Hanto Controlled Hunting Area, Southeastern Ethiopia. J Biodivers Endanger Species 5: 190. doi:10.4172/2332-2543.1000190

Page 4 of 7

The proportions of age and sex categories of mountain nyala in the study area are shown in Table 2. Out of a total number of 112 observed individuals of mountain nyala during the present study, 28 (25\%) were adult male, $40.4(36.2 \%)$ adult females, $14(12.5 \%)$ sub-adult male, 16.5
(14.7\%) sub-adult female and $13(11.6 \%)$ were young of both sexes. There was no significant difference $\left(\chi^{2}=0.2, \mathrm{df}=1, \mathrm{P}>0.05\right.$ and $\chi^{2}=0.04$, $\mathrm{df}=1, \mathrm{P}>0.05)$ between the mean number of males and females observed during the two seasons.

\begin{tabular}{|c|c|c|c|c|c|c|c|c|c|c|}
\hline \multirow{2}{*}{$\begin{array}{l}\text { Types } \\
\text { Animal }\end{array}$} & \multirow{2}{*}{ Season } & \multicolumn{5}{|c|}{ Age and Sex Category } & \multicolumn{4}{|c|}{ Ratio } \\
\hline & & AM & AF & SAM & SAF & Young & M:F & A:All & Y:All & Y:F \\
\hline \multirow{4}{*}{ Mountain nyala } & Wet & 24 & 37 & 11 & 14 & 10 & 01:01.5 & $1.74: 1$ & 01:08.6 & 01:05.1 \\
\hline & Dry & 32 & 44 & 17 & 19 & 16 & 01:01.3 & $1.46: 1$ & 01:07.0 & 01:03.9 \\
\hline & Mean & 28 & 40.5 & 14 & 16.5 & 13 & \multirow{2}{*}{ 01:01.4 } & \multirow{2}{*}{$1.57: 1$} & \multirow{2}{*}{ 01:07.6 } & \multirow{2}{*}{ 01:04.4 } \\
\hline & $\pm \mathrm{SE}$ & \pm 2.5 & \pm 2.2 & \pm 1.9 & \pm 1.6 & \pm 1.9 & & & & \\
\hline
\end{tabular}

Where: AM: Adult Male; AF: Adult Female; SAM: Sub-Adult Male; SAF: Sub-Adult Female; M: Male; F: Female, A: Adult, Y: Young

Table 2: Age and sex ratio of mountain nyala during wet and dry seasons.

On average, $61.2 \%$ of the total population was adult, $27.2 \%$ was subadult and only $11.6 \%$ was young for mountain nyala. There was significant difference in age category of adult to sub-adult and adult too young for mountain nyala in both seasons $\left(\chi^{2}=14.59, \mathrm{df}=1, \mathrm{p}<0.05\right.$ and $\left.\chi^{2}=37.79, \mathrm{df}=1, \mathrm{p}<0.05\right)$, respectively.

During the study period the groups (clusters) observed for mountain nyala are groups composed of all males, all females group, male and female group, females and young group, and mixed groups of both sexes and young. There was no significant difference in the mean group of the animal $\left(\chi^{2}=0.06, \mathrm{df}=1, \mathrm{p}>0.05\right)$ counted during the dry and wet seasons (Table 3). Throughout the study period, the most commonly observed groups were groups containing 5-10 individuals. The most frequently observed group size of mountain nyala were group of 6 animals in the wet season and 3 animals in the dry season. The highest range of group size was recorded during the wet season (1-16). Mean group size and the total number of groups observed during the wet season was minimal. While, during the dry season the total number of groups observed and the mean group sizes recorded were the highest. There were differences in the group size of mountain nyala, across different habitat. The largest groups were observed in the Erica vegetation and the smallest group in bamboo habitat.

\begin{tabular}{|l|l|l|l|l|l|}
\hline $\begin{array}{l}\text { Animal } \\
\text { Type }\end{array}$ & Season & $\begin{array}{l}\text { Individuals } \\
\text { observed }\end{array}$ & $\begin{array}{l}\text { Number of } \\
\text { groups }\end{array}$ & $\begin{array}{l}\text { Group } \\
\text { range }\end{array}$ & $\begin{array}{l}\text { Mean } \\
\text { group } \\
\text { size }\end{array}$ \\
\hline \multirow{2}{*}{$\begin{array}{l}\text { Mountain } \\
\text { Nyala }\end{array}$} & Wet & 96 & 18 & Jan-16 & 5.3 \\
\cline { 2 - 6 } & Dry & 128 & 23 & Jan-13 & 6.1 \\
\cline { 2 - 6 } & Mean & 112 & 20.5 & $1-14.5$ & 5.6 \\
\hline
\end{tabular}

Table 3: Group size of mountain nyala during wet and dry seasons.

The number of individuals observed in each habitat type for mountain nyala are given in Table 4. Mountain nyala showed high preference (frequently observed) for Erica vegetation during both dry and wet seasons. Out of the 96 individuals of the Mountain nyala observed in the wet season, $55.2 \%$ of the total population utilized Erica habitat during the wet season whereas, $56.3 \%$ of the population used the same habitat during dry season. There was no significant difference in use of Erica habitat in dry and wet season $(\chi 2=2.8, \mathrm{df}=1, \mathrm{P}>0.05)$. In addition on average during both seasons mountain nyala showed habitat preferences of $17.4 \%, 13.8 \%, 10.3 \%$ and $2.7 \%$ for reverin forest, woodland, grassland and bamboo forest respectively. There is significant difference in distribution of mountain nyala $\left(\chi^{2}=96.7, \mathrm{df}=4\right.$, $\mathrm{p}<0.05$ ) among the habitat types.

\begin{tabular}{|l|l|l|l|l|l|l|l|}
\hline \multirow{2}{*}{ Animal Type } & \multicolumn{5}{|c|}{ Habitat Type } & \multicolumn{2}{|c|}{} \\
\cline { 2 - 8 } & Seasons & Erica Forest & Woodland & Reverin Forest & Bamboo Forest & Grass land & Total \\
\hline \multirow{2}{*}{ Mountain nyala } & Wet & $53(55.2)$ & $14(14.6)$ & $15(15.6)$ & - & $14(14.6)$ & 96 \\
\cline { 2 - 8 } & Dry & $72(56.3)$ & $17(13.3)$ & $24(18.8)$ & $6(4.7)$ & $9(7)$ & 128 \\
\hline & Mean & $62.5(55.8)$ & $15.5(13.8)$ & $19.5(17.4)$ & $3(2.7)$ & $11.5(10.3)$ & 112 \\
\hline
\end{tabular}

Table 4: Number of individuals observed in each habitat type and their percentage. 


\section{Discussion}

In order to manage the population of endemic mountain nyala properly in the CHA and to decide (to set quota) on the number of animals to be hunted per year, estimating the population size, their distribution and structure in the study area are very important. During the study period more mountain nyala was counted in the dry seasons than wet season. The most plausible reason for this might be human activity such as collection of firewood and harvesting of grass was high during the wet season. Livestock encroachment is very high in the $\mathrm{CHA}$. This might affect the foraging opportunities of mountain nyala, thereby reducing the sighting.

Cultivation at lower altitudes during the wet season leads to the displacement of livestock into the high altitudes. However, during the dry season, after crops were harvested, livestock and pack animals move to lower altitude. Seasonality in the abundance of livestock grazing was also observed in Mount Kaka and Hunkolo Fragments, Southeast Ethiopia. Several studies in different localities have also revealed the adverse effect of livestock encroachment and human settlement on the abundance and distribution of wild animals [9].

It is difficult to assess the long term population trend of mountain nyala in Hanto CHA, as periodic censuses have not been conducted in the CHA. However, information's collected from local people and CHA scouts indicated that before the establishment of the CHA the number of mountain nyala were not more than thirty. Particularly, around 1991 during government change in Ethiopia, sever loss of wildlife encountered in the area. But now the populations of animals are increasing since 1998 after the establishment of the CHA. According to the CHA managers and local peoples the animals where highly hunted before the establishment of the CHA mainly for bush meat. However, there were no illegal hunting of the animals reported after the establishment. This might be because of high penalty and the protection of the CHA by the Rocky valley scouts and awareness creation on local people.

The concept of sex ratio and age structure of individual animal is vital for evaluating the viability of a species for the reason that, these variables reflect the structure and the dynamics of population [5]. Sex and age structure of a population at any given point of time is also an indicator of the status of the population. Therefore, relatively the higher population number of females in the CHA (male: female $=1: 1.36$ ) is beneficial in terms of adding more individuals to the population through birth.

Therefore, the current observation indicates a healthy and a possibility of increasing mountain nyala population in the CHA area. Young productivity was 0.32 young per adult female ( 32 young per 100 adult females). Relatively, the higher productivity of young observed in this study supports the previous study by Hillman [25] in Bale Mountain National Park. On the other hand, the high proportion of adults in the present study could indicate higher degree of survival of sub-adults.

Relatively low proportion of young to other age groups, 1:7.6 were observed during the present investigation. This might be the young ones are more vulnerable to predators and hidden under the dense grasses and vegetation. This supports the findings of Wronski [28] and Dereje et al. [6] which confirmed that at the early stage of their lives the young's are highly vulnerable to predation. On the other hand, low Proportion of sub-adults to others in the present investigation shows a problem of long term survival of the young in the area. Probably this was due to the high number of predators such as common jackal, spotted hyena, leopard and domestic dog in the CHA. During survey, the young of mountain nyala killed by domestic dog were encountered in the area.

The sex ratio of males was small. This might be largely due to probability of increase in killing of male mountain nyala due to predation. The male animals leave the natal herd and distributed in less favourable habitats, and suffer an increased predation pressure compared with the females of the same age classes, which stay in the natal herd [27] also confirmed that, the young female ungulates maintain their relationship with their mother group for some time after weaning. Young males, however, may soon become displaced because of antagonistic behavior from other males. The other reason observed for lower number of male animals in the CHA could be, because of male-biased selective hunting practices in the area. As the area is established for trophy hunting, adult males have been hunted by professional hunters (up to 6 individuals per year were hunted). For trophy hunters the cost for male mountain nyala was $\$ 15000$ [29].

During the study period the groups (clusters) observed for mountain nyala was social group's composed different age and sex categories. A group of all males, all females, male and female group, females and young group, and mixed groups of both sexes and young were observed. The current observation is similar with the previous study by Hillman [25] in BMNP. For mountain nyala, throughout the study period, the most commonly observed groups were groups containing 5-10 individuals. Even though, the average group size of the species remained relatively constant over the course of the present study, large groups were also observed in few cases.

Even though, large group sizes were recorded during the wet season, there was no significant difference between seasons. The possible reason for the increase in group size during the wet season compared to the dry season might be due to the availability of resources (food and water) minimizing competition between them. Similar observations were also made for mountain nyala by Evangelista et al.; Yosef et al. $[30,31]$ in BMNP. However, these averages may vary due to population density, limited habitat, the season of the year and the availability of forage and water.

During investigation, it was seen that some census zones had higher number of individual animals than others. The variations in census zones might be due to habitat quality, influence of human activities and livestock distribution and availability of resource in the area. Habitat quality is associated with the palatability of the plant, height of the grass and less disturbance. Similar studies of Yosef [31] in BMNP revealed that, resource distribution affects the distribution of animals. During the study period Mountain nyala were observed in all the five habitat type but with different number of individuals (Table 4).

Even though, the Mountain nyala were evenly distributed in the $\mathrm{CHA}$; it showed high preference for Erica vegetation during both dry 
and wet seasons. Out of the total individuals of Mountain nyala observed in the wet season, $55.2 \%$ of the total population utilized Erica habitat. In the same manner, $56.3 \%$ of the total population of mountain nyala were used this habitat during the dry season. However, it is less distributed in bamboo forest habitat. This type of habitat selection may be influenced by vegetation type, the presence of water, topographical features, predator avoidance and availability of food and other environmental factors among habitats and between seasons within each habitat. Regarding mountain nyala distribution, the possible reason could be the Erica vegetation was the main source of food and cover in both dry and wet seasons. The Erica vegetation is relatively green both seasons. In addition, in the study area, the Erica vegetation is found relatively at higher elevation where human and livestock disturbance is less. The present observation shows similarity with findings of Yosef et al.; Evangelista et al. [32,33] in BMNP and Zerihun et al. in Mount Kaka and Hunkolo Fragments. These investigators noted that Erica is one of major source of food for mountain nyala. And also mountain nyala prefers habitats that are relatively free of human and livestock disturbance.

In general, the present study indicated that, the abundance of endemic mountain nyala in Hanto CHA is relatively high and promising. Particularly, the current finding was a good news for the endanger mountain nyala population. But, even though there is a sign of recovery, still the wildlife of the CHA is facing a number of conservation threats. If proper conservation measures are taken, there is a possibility of population of the endemic wildlife to increase further.

\section{Conclusion}

The present investigation provides valuable information on abundance, distribution and structure of endemic and endangered mountain nyala in Hanto controlled hunting area. The study revealed that, the CHA harbors significant populations of mountain nyala. As a result, it can serves not only as hunting concession but also as an important core protected area for the country's wildlife conservation and tourist attraction area in the future. Relatively more females as compared to males observed in the CHA shows a healthy population of those species in the area. However, as the study site is hunting area, it needs continuous monitoring of the abundance and related problems in the area. Regarding the distribution of the animals Erica vegetation is the most important preferable habitat in the study area. Moreover, the information obtained about the specie, will also help for quota setting in trophy hunting and for the development of management plan for the conservation activities of the CHA.

However, due to human population increase, human activities like, encroachment to the wildlife habitat, deforestation, animal husbandry, agricultural expansions, dry season forest fire are fueling the loss, degradation and fragmentation of habitats of wildlife. As a result, the CHA needs strong attention and immediate action of stakeholders to work hand in hand to integrate indigenous knowledge and modern conservation systems to develop a better understanding of the benefits of wildlife and their ecosystems conservation. Generally, this study was the first formal investigation on abundance, distribution and structure of mountain nyala in the study area. Hence, the findings could serve as a baseline to make comparison against future research findings on the ecology of species in the CHA.

\section{Conflicts of Interest}

The authors did not declare any conflict of interest.

\section{Acknowledgement}

This study was carried out with the financial assistance of Madda Walabu University. Therefore, we are gratitude to Madda Walabu University for the financial assistances. We are also grateful to all the wildlife scouts of Hanto controlled hunting area for their strong commitment and participation during field data collection.

\section{References}

1. Kingdon J (1997) The kingdon field guide to African animals. Academic Press, San Diego.

2. Shimelis A, Afework B (2008) Species composition, relative abundance and distribution of bird fauna in riverine and wetland habitats of Infranza, Yiganda at southern tip of Lake Tana: Ethiopia. J Trop Ecol 49: 199-209.

3. Melaku T (2011) Wildlife in Ethiopia: endemic large animals. World J Zool 6: 108-116.

4. Shibiru T (1995) Protected areas management crisis in Ethiopia. Walia 16: 17-30.

5. Yalden D, Largen M, Kock D, Hillman J (1996) Catalogue of animals of Ethiopia and Eriteria (7). Revised checklist, zoogeography and conservation. Trop Zool 9: 73-75.

6. Dereje Y, Yosef M, Afework B (2011) Population ecology of Menelik's bushbuck (Traglaphus scriptus meneliki) from Denkoro Forest Proposed National Park: Northern Ethiopia. Int J Ecol Environ Sci 37: 1-13.

7. Yalden D, Largen M (1992) The endemic animals of Ethiopia. Mammal Review 22: 115-150.

8. Yosef M (2015) Demography and population dynamics of mountain nyala (Tragelaphus buxtoni) before its population crash in 1991 in the Bale Mountains National Park: Ethiopia. Int J Dev Res 5: 3085-3094.

9. Stephens P, Candy A, Sillero-Zubiri C, Leader-Williams N (2001) Impact of livestock and settlement on the large mammalian wildlife of Bale Mountains National Park: Southern Ethiopia. Biological Conservation 100: 307-322.

10. Institute of Biodiversity Conservation (2007) Wild animal genetic resource of Ethiopia. Addis Ababa Ethiopia.

11. Aramde F, Girma M, Tsegaye B (2011) Spatial distribution and habitat preferences of selected large mammalian species in the Nech Sar National Park, Ethiopia. Nat Sci 9: 80-90.

12. Biodiversity Indicators Development National Task Force (2010) Ethiopia: Overview of selected biodiversity indicators. Addis Ababa.

13. Anagaw A, Loe L, Langangen, Rueness E, Bekele A, et al. (2011) Estimating abundance and habitat suitability for mountain nyala in areas with different protection status. J Anim Conserv 14: 409-418.

14. Yalden D, Largen M, Kock D (1984) Catalogue of the animals of Ethiopia-Artiodactyla. Monitoring Zoology 19: 67-221.

15. Malcolm J, Evangelista P (2011) Observations on the Status of the Mountain Nyala: 2000-2005. Walia Special Edition on the Bale Mountains.

16. International Union for Conservation of Nature (2013) Tragelaphus buxtoni In: IUCN.

17. Lindsey P, Roulet P, Romanach S (2007) Economic and conservation significance of the trophy hunting industry in Sub-Saharan Africa. Biol Cons 134: 455-469.

18. (2013) Oromia Forest and Wildlife Enterprise Report. Addis Ababa.

19. Buckland S, Anderson D, Burnham K, Laake J (1993) Distance sampling: estimating abundance of biological populations. Chapman and Hall, London.

20. Sutherland J (1996) Ecological census technique, Hand Book. Cambridge University Press, Cambridge.

21. Girma M, Afework B (2008) Diversity, distribution and habitat association of large animals of Altish, North Gonder: Ethiopia. Acta Zoologica Sinica 5: 20-29. 
Citation: Worku D, Datiko D (2017) Abundance, Distribution and Population Structure of Mountain Nyala (Tragelaphus buxtoni) in Hanto Controlled Hunting Area, Southeastern Ethiopia. J Biodivers Endanger Species 5: 190. doi:10.4172/2332-2543.1000190

Page 7 of 7

22. Norton-Griffiths M (1979) Counting animals East African Wildlife foundation, Nairobi.

23. Buckland S (2001) Introduction to distance sampling: estimating abundance of biological populations. Oxford University Press, Oxford.

24. Befekadu R, Afework B (2004) Population status and structure of mountain nyala in the Bale Mountains National Park: Ethiopia. Afr J Ecol 42: $1-7$

25. Hillman J (1986) Bale mountains national park management plan. Ethiopian Wildlife Conservation Organization, Addis Ababa.

26. Yosef M, Addisu A, Girma M (2015) Social organization in the mountain nyala (Tragelaphus buxtoni) population in Bale Mountain National Park, Ethiopia. Int J Biodivers Conserv 7: 103-111.

27. Norton-GM (1978) Counting animals (2nd edn.). Africa Wildlife Leadership, Nairobi.

28. Wronski $\mathrm{T}$ (2004) The social and spatial organization of Bushbuck (Tragelaphus scriptus )Pallas 1776) in Queen Elizabeth National Park, Uganda, Ph.D. Thesis, University of Hamburg, Germany.
29. Ethiopian Wild life Conservation Authority (2012) Ethiopian wild life conservation authority 2012 report. Addis A, Ethiopia.

30. Evangelista P, Swartzinski P, Waltermire R (2007) A profile of the mountain nyala (Tragelaphus buxtoni). African Indaba 5: 1-47.

31. Yosef M, Michelle A, Afework B (2010) Demography and dynamics of mountain nyala (Tragelaphus buxtoni) in the Bale Mountains National Park: Ethiopia. Curr Zool 56: 660-669.

32. Yosef M, Afework B (2011) Human and livestock encroachments into the habitat of Mountain Nyala (Tragelaphus buxtoni) in the Bale Mountains National Park: Ethiopia. Trop Ecol 52: 265-273.

33. Evangelista P, Norman J, Swartzinski P, Young N (2012) Assessing habitat quality of the mountain nyala (Tragelaphus buxtoni) in the Bale Mountains: Ethiopia. Curr Zool 58: 525-535.s 